\title{
Development of Procamallanus saccobranchi (Nematoda: Camallanidae), a parasite of a freshwater fish in India
}

\author{
Nimai C. De and Rabindra N. Maity \\ Helminthology Laboratory, Zoology Department, Kalyani University, Kalyani, West Bengal, 741235, India
}

Key words: Nematoda, Procamallanus, fish, Heteropneustes, Copepoda, Mesocyclops, development

\begin{abstract}
The development of the nematode Procamallanus saccobranchi Karve, 1952, a parasite in the stomach of the fish Heteropneustes fossilis (Bloch), was studied in Mesocyclops crassus (Fischer) and Mesocyclops leuckarti (Claus). After being ingested by the copepods the nematode first-stage larvae penetrated into the haemocoel of the intermediate host; there they moulted twice (on days 3 and 5 p.i. at $28-30^{\circ} \mathrm{C}$ ) attaining the third, infective stage. The definitive host $H$. fossilis acquired infection by feeding on copepods harbouring infective-stage larvae; in the stomach of this definitive host, the larvae were observed to undergo two more moults. The third moult occurred on day 13 p.i. and the fourth moult on day 38 p.i. and day 66 p.i. in "male" and "female" larvae, respectively. The larval stages, including the moulting forms are described and illustrated.
\end{abstract}

Procamallanus saccobranchi Karve, 1952 is a common nematode parasite in the stomach of the freshwater fish, Heteropneustes fossilis (Bloch). De et al. (1986) studied the development of Procamallanus spiculogubernaculus Agarwal, 1958 (=P. saccobranchi) (see Roy 1987) in an intermediate copepod host. Subsequently, Sinha (1988) again described its life cycle, though inadequately. The development of only two other species of the genus Procamallanus Baylis, 1923 (Moravec 1975, Wang and Ling 1975) has been studied. As to the other related genera, the development of only six species of the genus Spirocamallanus Olsen, 1952 (Li 1935, Pereira et al. 1936, Bashirullah and Ahmed 1976, Fusco 1980, De 1995, Moravec et al. 1995 and Moravec and Vargas-Vázquez 1996) and one species of the genus Onchocamallanus Petter, 1979 (De and Maity 1999) has been worked out so far. The present communication deals with the results obtained from experimental observations on the development of $P$. saccobranchi in intermediate and definitive hosts.

\section{MATERIALS AND METHODS}

The larvated females of $P$. saccobranchi, recovered from the stomach of naturally infected fish, $H$. fossilis, were rinsed thoroughly in $0.85 \%$ saline and transferred to small Petri dishes (4 worms in each) containing filtered tap water and kept overnight at room temperature to permit them to release larvae. The spent females were taken out and the content of each Petri dish was poured into a $250 \mathrm{ml}$ glass beaker containing filtered pond water and 50 previously starved laboratory-reared copepods, Mesocyclops crassus (Fischer) and Mesocyclops leuckarti (Claus). After being exposed for two hours the copepods from each beaker were transferred to separate $500 \mathrm{ml}$ beakers three-fourth of which had been previously filled up with filtered pond water and kept at 28$30^{\circ} \mathrm{C}$. A few algal filaments were added to each beaker.
Twenty-five copepods from each beaker were examined under low magnification to determine infection of the copepods. To study larval development, copepods from each beaker were teased by fine needles on a glass slide and examined by light microscopy at 2-hour intervals after an initial 24 hours infection period. Later, the intervals were gradually increased. For experimental infection a total of 37 fish, H. fossilis, reared in the laboratory and fed dry food only, were used. To infect fish 5-10 infected copepods (each harbouring 1-5 third-stage larvae) were forcibly pushed into the stomach of each fish by means of a long-nozzled dropper. The fish were maintained in an aquarium (temperatures ranging between 27 and $31^{\circ} \mathrm{C}$ ) and were sacrificed between 12 and 66 days post infection (p.i.), for collecting nematodes present. All larvae i.e. those obtained from the haemocoel of the cyclops and stomach of the fish were killed by gentle heating and fixed in $10 \%$ formalin. After being cleared in $2 \%$ glycerol the larvae and young males and females were examined by light microscopy. All measurements are in micrometres except when mentioned otherwise. Metrical data given in the text are also included in tables 1 and 2 .

\section{RESULTS}

\section{EXPERIMENTAL INFECTION OF THE COPEPODS}

After entering the gut of the copepods the ingested larvae pierced through the intestinal wall by means of the dorsal cuticular tooth to reach the haemocoel of the host. In the haemocoelic cavity of the copepods the larvae were found to undergo two moults to attain the third stage. A phase of growth, development and morphometric changes occurs between the two moults. The first moult occurred at the beginning of day 3 p.i. (56 and $58 \mathrm{~h}$ ). Almost all the larvae attained the second stage before day 4 p.i. The second moult occurred at the beginning of day 5 p.i. (102 h) and thus the third-stage larvae first appeared on day 5 p.i. and remained 


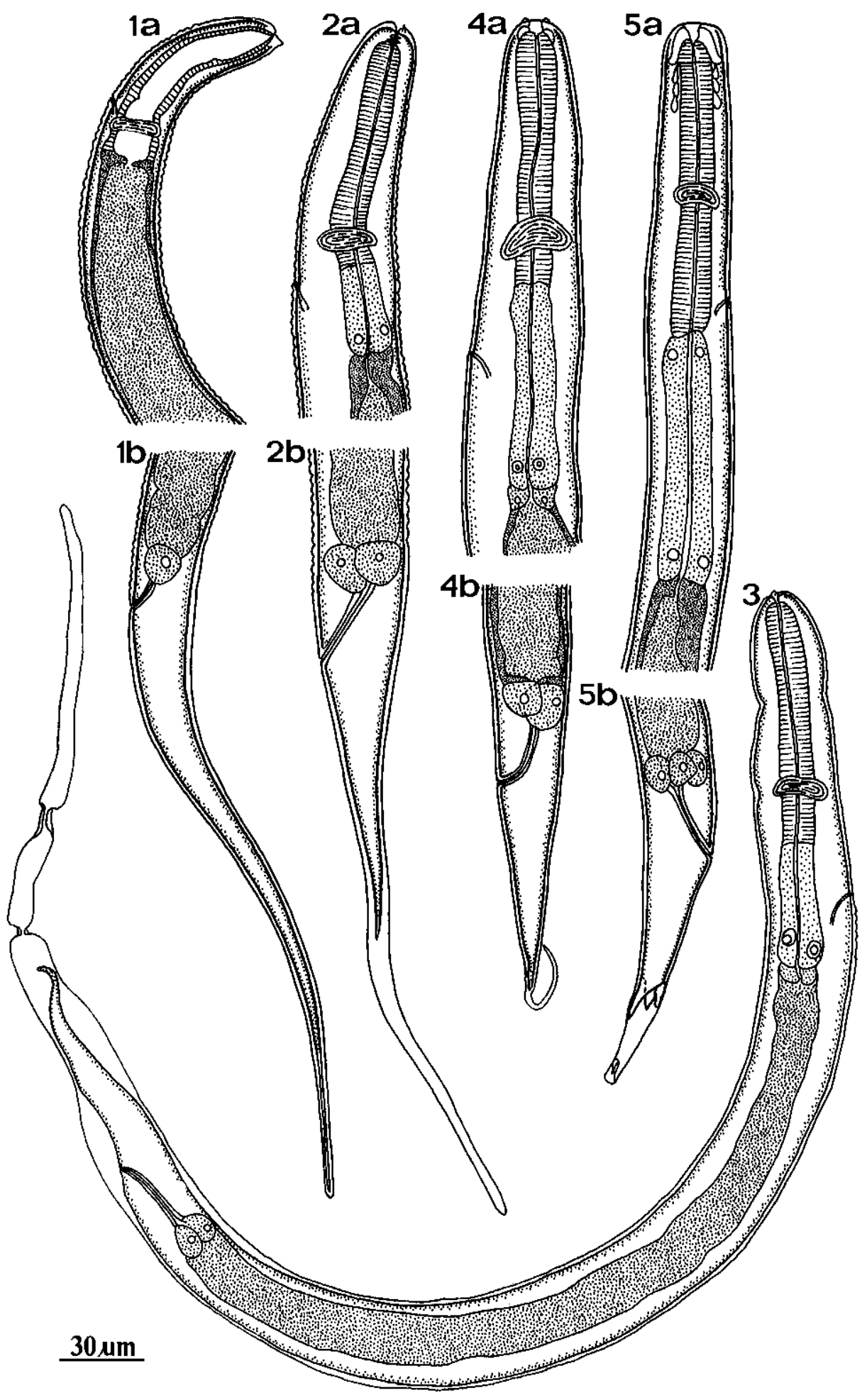

Figs. 1-5. Procamallanus saccobranchi. Fig. 1. Free first-stage larva (a - anterior end of body, b - tail end). Figs. 2-5. Development of larva in copepod. Fig. 2. Larva preparing for first moult on hour 57 p.i. (a - anterior end of body, b - tail end). Fig. 3. Larva during first moult on hour 56 p.i. Fig. 4. Second-stage larva on hour 61 p.i. (a - anterior end of body, b - tail end). Fig. 5. Larva preparing for second moult on hour 102 p.i. ( $\mathrm{a}$ - anterior end of body, $\mathrm{b}$ - tail end). 

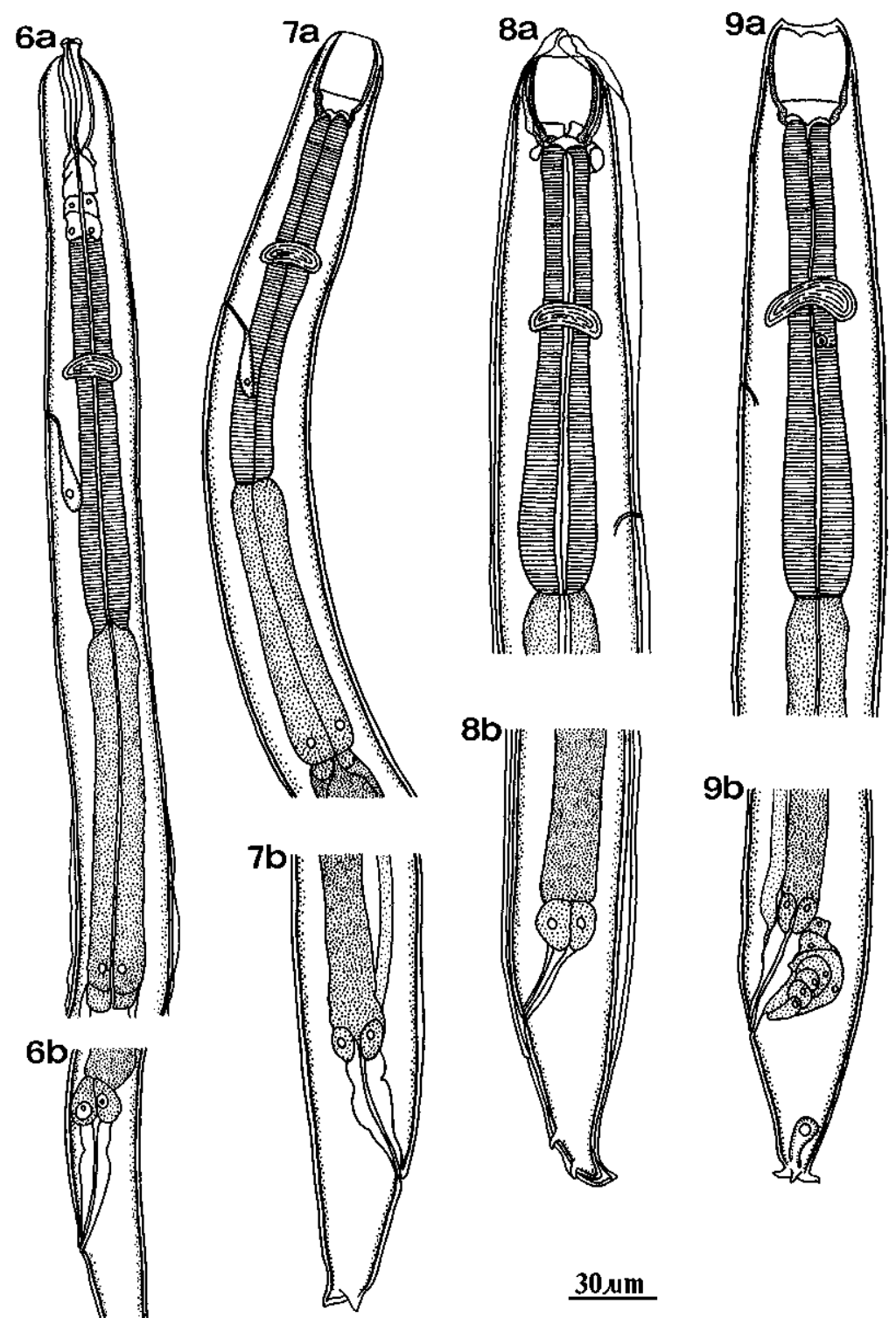

$30 \mu \mathrm{m}$

Figs. 6-9. Procamallanus saccobranchi. Figs. 6, 7. Development of larva in copepod. Fig. 6. Larva just after second moult on hour 102 p.i. ( $\mathrm{a}$ - anterior end of body, $\mathrm{b}$ - tail end). Fig. 7. Third-stage larva on hour 110 p.i. ( $\mathrm{a}$ - anterior end of body, $\mathrm{b}-$ tail end). Figs. 8, 9. Development of larva in fish. Fig. 8. Larva during third moult, on day 13 p.i. (a - anterior end of body, b - tail end). Fig. 9. Fourth-stage "male" larva on day 13 p.i. ( $\mathrm{a}$ - anterior end of body, b-tail end).

coiled in the haemocoelic cavity of the abdomen and the cephalothorax of the copepods. Considerable morphological changes, including development of the large yellowish-brown, well sclerotised buccal capsule and the three mucrones at the tail tip were noted at this stage.

In the present series of experiments the prevalence of infection of the copepods was $35 \%(n=1022)$ and the range of the intensity varied between 1 and 5 (average 2).

\section{EXPERIMENTAL INFECTION OF THE FISH}

The copepods containing third-stage larvae were forcibly pushed into the stomach of 37 laboratory-reared fish, $H$. fossilis. The larvae were found to grow and moult twice in the stomach of the fish. The larvae 
undergoing the third (first in the definitive host) moult were obtained on day 13 p.i. and the fourth-stage "male" and "female" larvae were also first recovered on day 13 p.i. The fourth i.e. final moult occurred at different times for the "male" and "female" larvae, on day 38 p.i. in the former but on day 66 p.i. in the latter. Young male and young female worms were also collected on day 38 and 66 p.i., respectively, and later.

\section{MORPHOLOGY AND LARVAL DEVELOPMENT}

\section{First-stage larvae}

First-stage larvae from female uteri $(n=15) \quad$ Figs. 1a,b

Body slender, translucent and tapering at both ends; 369-544 long and 13-26 wide. Body cuticle thick with fine transverse striations. Head end dorsally bent and provided with a small dorsal cuticular tooth. Short and narrow buccal tube (2-4 long) opens into thin-walled oesophagus (49-76 long) with spacious cavity inside. Nerve-ring surrounds oesophagus at its posterior half (34-65 from anterior end). Excretory pore slightly anterior to nerve-ring (30-57 from cephalic end). Straight, wide intestine with fine granulation inside and leading posteriorly to short narrow rectum; three gland cells present at their junction. Tail elongate, conical and 155-229 long.

First-stage larvae from the copepod hosts $(n=44)$

Figs. 2a, b

In the haemocoelic cavity of the copepod hosts the larvae initially show a moderate increase of their body measurements. Between days 1 and 5 p.i. (at water temperatures $28-30^{\circ} \mathrm{C}$ ), larvae $387-643$ long and 15-38 wide. Dorsal cuticular tooth still present. Both body cuticle and wall of oesophagus become thickened and thus spacious oesophageal cavity turns to a narrow lumen. Oesophagus 53-132 long with indistinctly separated anterior muscular and posterior glandular moieties. Nerve-ring encircles oesophagus at 36-81 from anterior extremity. Excretory pore posterior to nerve-ring, 43-106 from head end. Long and wide intestine with small granules inside. Short and narrow rectum with large, oval rectal gland cells at its junction with intestine. Tail elongate (83-189 long) and slender.

\section{Second-stage larvae}

Moulting first-stage larvae $(\mathrm{n}=2)$

Fig. 3

Larvae during first moult possess long, slender body (545, 646 long and 30, 40 wide) with thin and smooth cuticle. Cephalic end rounded and without dorsal cuticular tooth. Oesophagus (133, 140 long) still indistinctly divided into anterior muscular and posterior glandular moieties. Two distinct cell nuclei at posterior wider portion of glandular oesophagus. Oesophagus leads to intestine through two small but distinct valves. Nerve-ring 68 and 83 from cephalic end. Excretory pore near middle of glandular oesophagus, 112, 120 from anterior extremity. Long and wide intestine leads posteriorly to short, narrow rectum. Three large, oval rectal gland cells at the junction of intestine and rectum. Tail elongate, conical and 79, 85 long.

Developed second-stage larvae $(\mathrm{n}=33)$

Figs. 4a, b, 5a, b

Second-stage larvae 488-961 long and 25-36 wide. Cuticle thin and smooth. A small hyaline "cap" at anterior end of muscular oesophagus. Oesophagus distinctly divided into anterior muscular (64-129 long) and posterior glandular (43-104 long) moieties. Posterior wider portion of glandular oesophagus with two distinct cell nuclei. Two small valves at oesophageo-intestinal junction. Nerve-ring 57-89 from anterior end. Excretory pore posterior to nerve-ring, 78123 from cephalic end. Long and wide intestine with dense granules. Thin-walled, narrow rectum with three large rectal gland cells at its junction with intestine. Tail conical and 45-76 long.

\section{Third-stage larvae from copepods}

Moulting second-stage larva $(\mathrm{n}=1)$

Figs. 6a, b

During second moult larva 1037 long and 35 wide. Cuticle smooth. Buccal capsule (39 long and 9 wide) narrow and feebly sclerotised. Oesophagus distinctly divided into anterior muscular (171 long) and shorter posterior glandular (131 long) moieties. Nerve-ring surrounds muscular oesophagus at its anterior half, 111 from head end. Excretory pore posterior to nerve-ring, 132 from anterior end. Intestine thin-walled, filled with a dense granular material and opens into tubular rectum; large rectal gland cells present at their junction. Tail 68 long and terminating in three distinct mucrones.

Third-stage larvae $(\mathrm{n}=27)$

Figs. 7a, b, 15-17

Third-stage larvae first appear on day 5 p.i. The development was studied until 21 days p.i. During this period larvae were 684-1068 long and 26-46 wide. Cuticle thick and transversely striated. Well sclerotised yellowish-brown buccal capsule (23-32 long and 13-21 wide) without striations. Oesophagus with anterior longer muscular (107-164 long) and posterior glandular (89-147 long) moieties. Two cell nuclei at wider portion of glandular oesophagus. Oesophagus leads to intestine through valves. Nerve-ring and excretory pore lie at $60-$ 96 and 89-117, respectively, from cephalic end. Straight, wide intestine leads to a short, narrow rectum with cuticular inner lining; three small rectal gland cells at their junction. Genital primordium starts developing, takes short, elongate form and contains some distinct cell nuclei (Figs. 15-17). Tail short (38-59 in length), with one large dorsal and two smaller subventral mucrones at distal end.

A summary (Table 1) of measurements of free larvae and larvae from the experimental copepod host is given separately. 

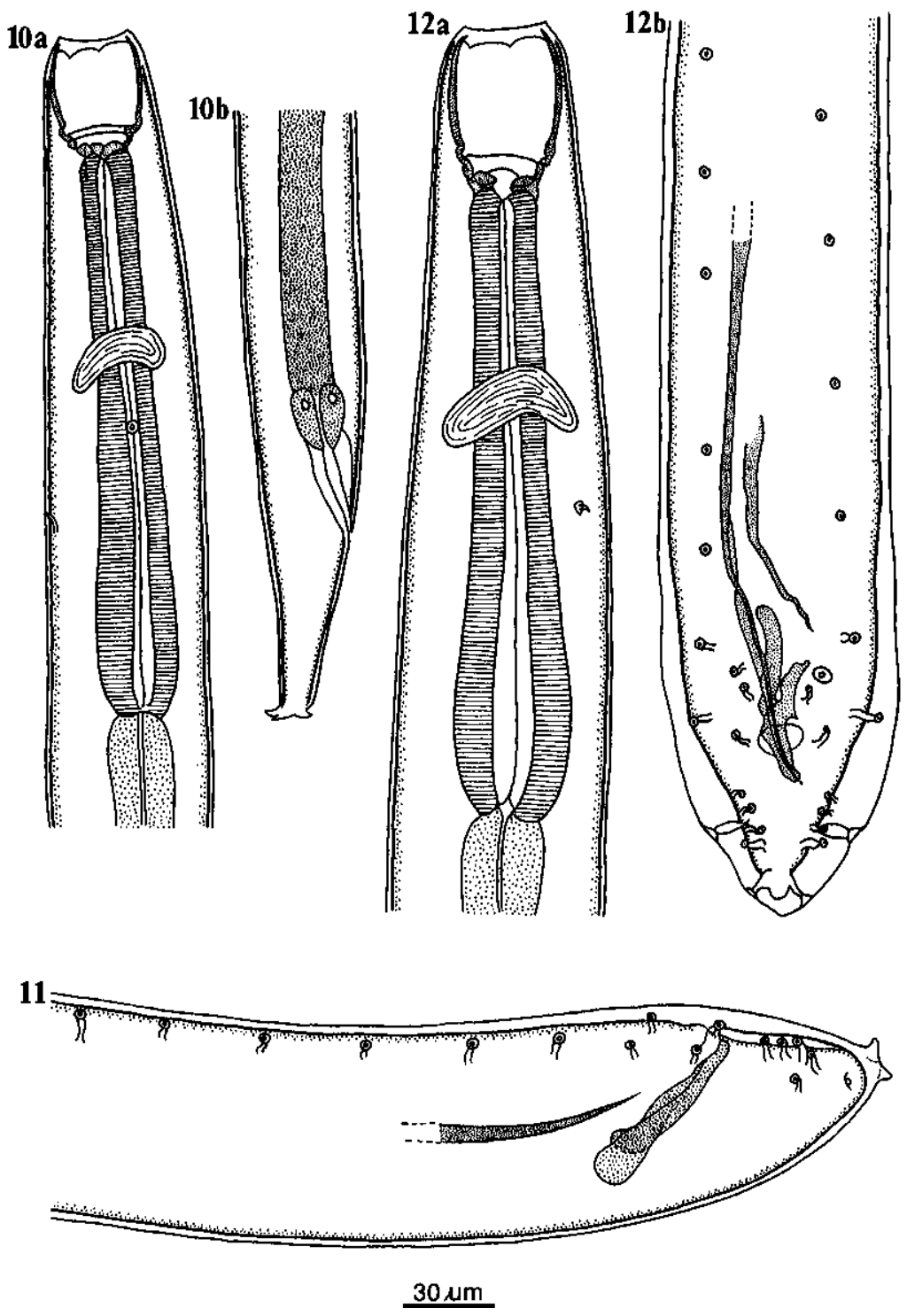

Figs. 10-12. Procamallanus saccobranchi, development of larva in fish. Fig. 10. Fourth-stage "female" larva on day 14 p.i. (a anterior end of body, b - tail end). Fig. 11. Tail end of "male" larva undergoing fourth moult on day 38 p.i. Fig. 12. Young male on day 38 p.i. ( $\mathrm{a}$ - anterior end of body, $\mathrm{b}$ - tail end).

\section{Third-stage larvae from the fish hosts $(\mathrm{n}=21)$}

Figs. 18,19

Third-stage larvae recovered from the experimentally infected fish ( $H$. fossilis) were observed between days 12 and 15 p.i. Morphology of these larvae was similar to that of infective-stage larvae obtained from copepods except for slightly larger body size and some internal organs (see Table 2). Genital primordia took elongate tubular form both in "male" and "female" larvae (Figs. $18,19)$.

\section{Fourth-stage larvae}

Moulting third-stage larvae $(\mathrm{n}=2)$

Figs. $8 \mathrm{a}, \mathrm{b}$

Larvae during third moult 1319, 1632 long and 49, 51 wide. Cuticle indistinctly striated. Buccal capsule 30 , 36 long and 19, 24 wide. Anterior muscular moiety of oesophagus $(159,170$ long) shorter than posterior glandular one (176, 185 long). Nerve-ring and excretory pore at 88,95 and 157,162 , respectively from anterior end. Tail $(60,68$ long) with five mucrones, one large dorsal and four smaller subventral. 

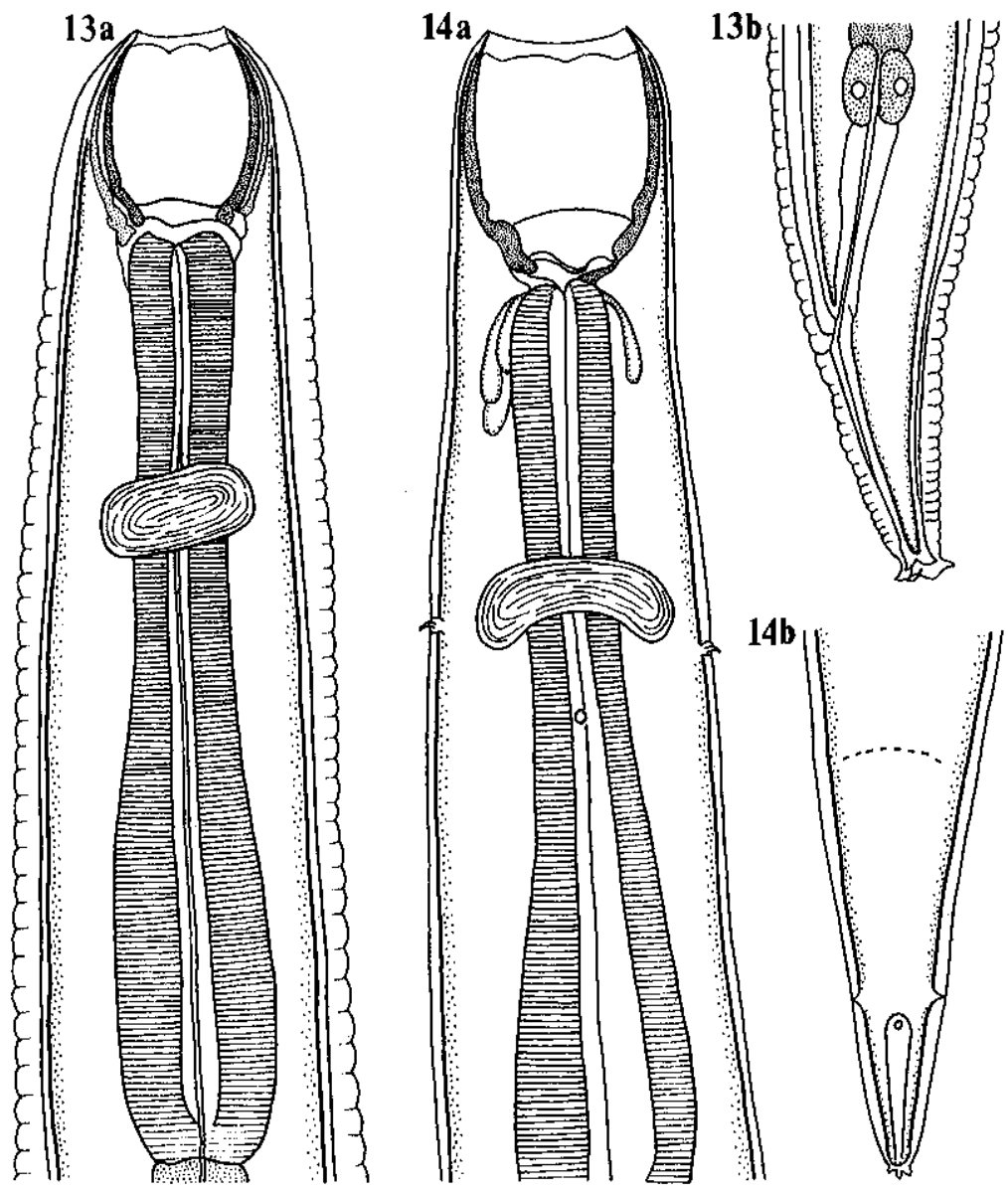

$\underline{30, \mathrm{Mm}}$

Figs. 13, 14. Procamallanus saccobranchi, development of larva in fish. Fig. 13. "Female" larva during fourth moult on day 66 p.i. ( $\mathrm{a}$ - anterior end of body, $\mathrm{b}$ - tail end). Fig. 14. Young female on day 66 p.i. ( $\mathrm{a}$ - anterior end of body, $\mathrm{b}$ - tail end).

Developed fourth-stage "male" larvae $(\mathrm{n}=9)$

Figs. 9a, b, 20

Fourth-stage "male" larvae (1625-1907 long and 3862 wide) possess transversely striated cuticle. Well sclerotised yellow-brown buccal capsule 32-38 long and 21-28 wide. Muscular and glandular moieties of oesophagus 163-180 and 176-202 long, respectively. Entire oesophagus 340-378 long. Nerve-ring and excretory pore at 85-98 and 128-161, respectively, from cephalic extremity. Deirids below nerve-ring level, 111118 from head end. A single reproductive tube with anterior testicular lobe, reaching posteriorly near proximal ventral part of rectum (Fig. 20). A number of cells found dorsal to rectum which probably take part in formation of accessory organs. Tail short, 53-66 long and with three small mucrones.

\section{Developed fourth-stage "female" larvae $(\mathrm{n}=15)$}

Figs. 10a, b, 21

Fourth-stage female larvae 1831-3052 long and 4377 wide. Cuticle transversely striated. Buccal capsule 36-48 long and 23-38 wide. Oesophagus with short muscular (170-221) and longer glandular (185-276) moieties. Entire oesophagus 355-486 long. Nerve-ring and excretory pore at 93-112 and 140-183, respectively, from anterior end. Deirids at 131-137 from cephalic end. Genital primordium a short tube (Fig. 21). Presumptive vulva seen posterior to mid body. Tail short (55-76 long) with three small mucrones.

\section{Young adults, fifth-stage}

"Male" larva undergoing fourth moult $(\mathrm{n}=1) \quad$ Fig. 11

"Male" larva during fourth moult 1938 long and 68 wide. Buccal capsule well formed (38 long and 28 
Table 1. Dimensions of Procamallanus saccobranchi larvae in the copepod intermediate hosts (in micrometres unless otherwise indicated).

\begin{tabular}{|c|c|c|c|c|c|c|c|c|c|}
\hline & \multicolumn{4}{|c|}{ First-stage larvae } & \multicolumn{3}{|c|}{ Second-stage larvae } & \multirow{2}{*}{\multicolumn{2}{|c|}{$\begin{array}{l}\text { Third-stage larvae } \\
\qquad(\mathrm{n}=27)\end{array}$}} \\
\hline & \multirow{2}{*}{$\begin{array}{l}\text { Free larvae } \\
\quad(\mathrm{n}=15)\end{array}$} & \multirow{2}{*}{$\begin{array}{c}\text { Unsheathed } \\
(\mathrm{n}=31)\end{array}$} & \multirow{2}{*}{$\begin{array}{c}\text { Sheathed } \\
(\mathrm{n}=13)\end{array}$} & \multirow{2}{*}{$\begin{array}{c}\begin{array}{c}\text { Moulting } \\
(\mathrm{n}=2)\end{array} \\
56 \text { hours, } \\
58 \text { hours p.i. }\end{array}$} & \multirow{2}{*}{$\begin{array}{c}\text { Unsheathed } \\
(\mathrm{n}=24) \\
60-76 \\
\text { hours p.i. }\end{array}$} & \multirow{2}{*}{$\begin{array}{c}\begin{array}{c}\text { Sheathed } \\
(\mathrm{n}=9)\end{array} \\
78-102 \\
\text { hours p.i. }\end{array}$} & \multirow{2}{*}{$\begin{array}{c}\begin{array}{c}\text { Moulting } \\
(\mathrm{n}=1)\end{array} \\
\begin{array}{c}102 \\
\text { hours p.i. }\end{array}\end{array}$} & & \\
\hline & & & & & & & & 5-10 days p.i. & 19-21 days p.i. \\
\hline Length of body (mm) & $0.369-0.544$ & $0.387-0.610$ & $0.435-0.643$ & $0.545,0.646$ & $0.488-0.771$ & $0.496-0.961$ & 1.037 & $0.684-1.068$ & $0.713-1.007$ \\
\hline Width of body & $13-26$ & $15-36$ & $23-38$ & 30,40 & $25-36$ & $26-36$ & 35 & $26-45$ & $28-46$ \\
\hline Length of buccal capsule & - & - & - & - & - & - & 39 & $23-31$ & $26-32$ \\
\hline Width of buccal capsule & - & - & - & - & - & - & 9 & $13-21$ & $15-19$ \\
\hline Length of muscular oesophagus & - & - & - & - & $64-112$ & $74-129$ & 171 & $110-164$ & $107-159$ \\
\hline Length of glandular oesophagus & - & - & - & - & $43-68$ & $53-104$ & 131 & $89-147$ & $117-142$ \\
\hline Length of entire oesophagus & $49-76$ & $53-117$ & $89-132$ & 133,140 & $115-172$ & $127-232$ & 263 & $204-312$ & $225-297$ \\
\hline Nerve-ring from anterior end & $34-65$ & $36-79$ & $43-81$ & 68,63 & $57-85$ & $64-89$ & 111 & $60-96$ & $70-95$ \\
\hline Excretory pore from anterior end & $30-57$ & $43-102$ & $64-106$ & 112,120 & $78-115$ & $87-123$ & 132 & $93-117$ & $89-113$ \\
\hline Length of tail & $155-229$ & $132-189$ & $83-110$ & 79,85 & $62-76$ & $45-64$ & 68 & $38-59$ & $40-54$ \\
\hline
\end{tabular}


Table 2. Dimensions of Procamallanus saccobranchi larvae and young adults in the definitive fish hosts, Heteropneustes fossilis (in micrometres unless otherwise indicated).

\begin{tabular}{|c|c|c|c|c|c|c|c|c|}
\hline & \multicolumn{2}{|c|}{ Third-stage larvae } & \multicolumn{2}{|c|}{ Fourth-stage "male" larvae } & \multicolumn{2}{|c|}{ Fourth-stage "female" larvae } & \multirow[b]{2}{*}{$\begin{array}{l}\text { Young males } \\
\quad(\mathrm{n}=2)\end{array}$} & \multirow[b]{2}{*}{$\begin{array}{l}\text { Young females } \\
\qquad(\mathrm{n}=3)\end{array}$} \\
\hline & $(\mathrm{n}=21)$ & $\begin{array}{l}\text { Third moult } \\
(\mathrm{n}=2)\end{array}$ & $(n=9)$ & $\begin{array}{l}\text { Fourth moult } \\
\quad(\mathrm{n}=1)\end{array}$ & $(\mathrm{n}=15)$ & $\begin{array}{l}\text { Fourth moult } \\
\quad(\mathrm{n}=2)\end{array}$ & & \\
\hline & 12-15 days p.i. & 13 days p.i. & 13-14 days p.i. & 38 days p.i. & 13-14 days p.i. & 66 days p.i. & 38 days p.i. & 66 days p.i. \\
\hline Length of body (mm) & $1.030-1.510$ & $1.319,1.632$ & $1.625-1.907$ & 1.938 & $1.831-3.052$ & $2.754,3.517$ & $2.403,2.456$ & $3.174-3.578$ \\
\hline Width of body & $32-57$ & 49,51 & $38-62$ & 68 & $43-77$ & 76,83 & 66,79 & $85-95$ \\
\hline Length of buccal capsule & $26-34$ & 30,36 & $32-38$ & 38 & $36-48$ & 49,53 & 45,52 & $53-67$ \\
\hline Width of buccal capsule & $15-23$ & 19,24 & $21-28$ & 28 & $23-38$ & 36,41 & 32,38 & $49-57$ \\
\hline Length of muscular oesophagus & $123-172$ & 159,170 & $163-180$ & 183 & $170-221$ & 242,257 & 195,212 & $227-266$ \\
\hline Length of glandular oesophagus & $132-187$ & 176,185 & $176-202$ & 202 & $185-276$ & 282,304 & 234,246 & $291-340$ \\
\hline Length of entire oesophagus & $253-365$ & 335,355 & $340-378$ & 386 & $355-486$ & 529,546 & 429,448 & $520-607$ \\
\hline Nerve-ring from anterior end & $72-91$ & 88,95 & $85-98$ & 98 & $93-112$ & 120,138 & 112,116 & $119-147$ \\
\hline Excretory pore from anterior end & $111-176$ & 157,162 & $129-161$ & 166 & $140-183$ & 191,198 & 180,188 & $188-208$ \\
\hline Length of left spicule & - & - & - & - & - & - & 66,79 & - \\
\hline Length of right spicule & - & - & - & - & - & - & 321,331 & - \\
\hline Vulva from posterior end (mm) & - & - & - & - & - & - & - & $1.29-1.64$ \\
\hline Length of tail & $42-72$ & 60,68 & $53-66$ & 54 & $55-76$ & 70,79 & 58,63 & $79-118$ \\
\hline
\end{tabular}




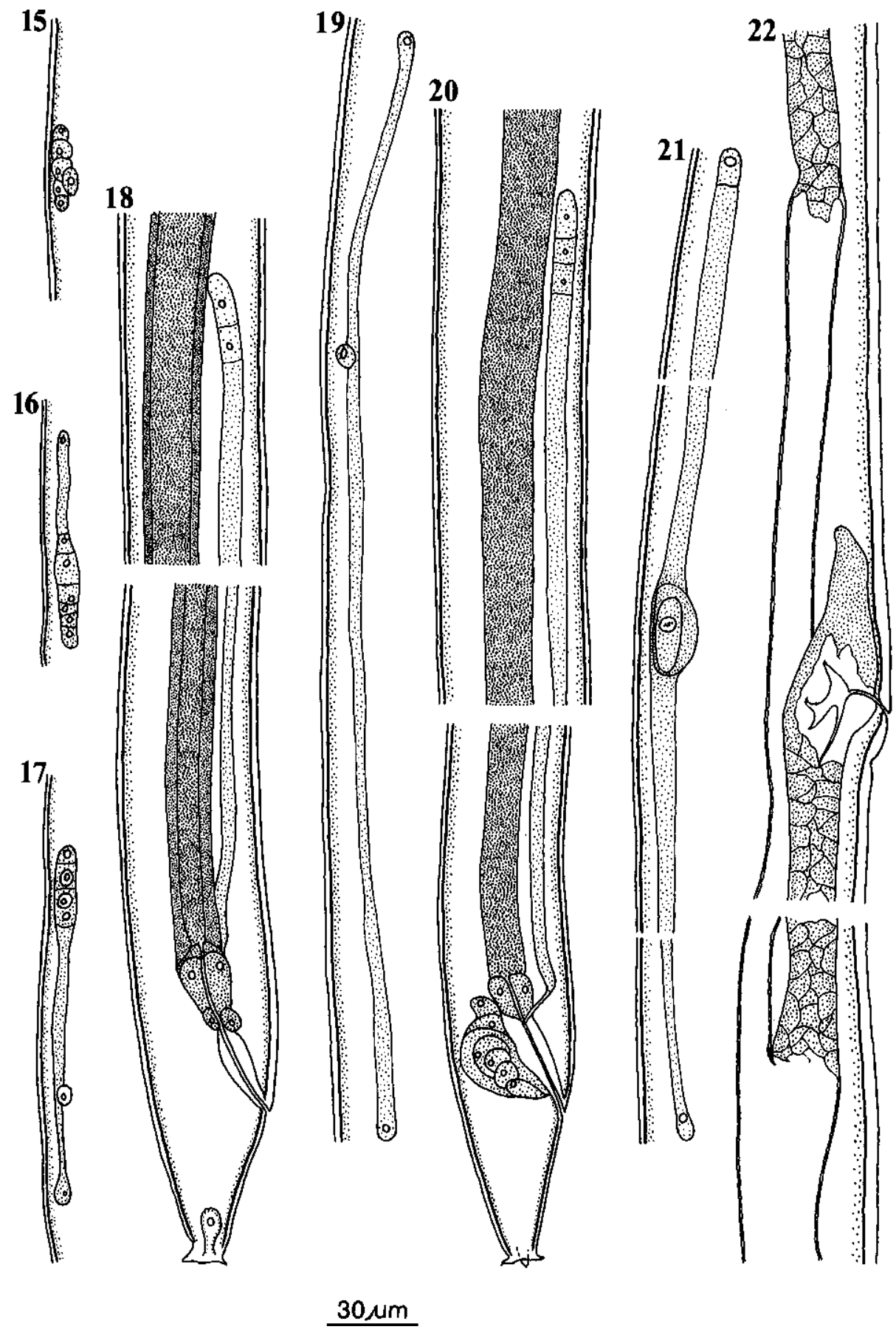

Figs. 15-22. Procamallanus saccobranchi. Figs. 15-17. Development of gonads in different larval stages from copepod. Fig. 15. Genital primordium in larva during last phase of second moulting on hour 102 p.i. Figs. 16, 17. Genital primordium in third-stage larva on day 10 p.i. Figs. 18-22. Development of gonads in different larval stages from fish. Fig. 18. Developing gonad in thirdstage "male" larva on day 10 p.i. Fig. 19. Developing gonad in third-stage "female" larva on day 10 p.i. Fig. 20. Developing gonad in fourth-stage "male" larva on day 13 p.i. Fig. 21. Developing gonad in fourth-stage "female" larva on day 14 p.i. Fig. 22. Vulva region of young female on day 66 p.i.

wide). Anterior muscular moiety (183 long) of oesophagus shorter than posterior glandular moiety $(202$ long). Nerve-ring encircles oesophagus at 98 from cephalic end. Excretory pore posterior to nerve-ring, 166 from head extremity. Both spicules and gubernaculum present. Amongst 15 pairs of caudal 
papillae: 9 pairs preanals, 1 pair adanals and 5 pairs postanals. Phasmids laterally posterior to last pair of postanal papillae. Tail 54 long, with obtuse tip.

"Female" larvae undergoing fourth moult $(n=2)$

Figs. 13a, b

"Female" larvae undergoing fourth moult 2754, 3517 long and 76, 83 wide. Cuticle indistinctly striated. Newly formed buccal capsules 49, 53 long and 36, 41 wide. Oesophagus with short anterior muscular (242, 257 long) and longer posterior glandular (282, 304 long) moieties. Distance of nerve-ring and excretory pore 120 , 138 and 191, 198, respectively, from cephalic end. Tail conical, 70, 79 long, with small mucrones at distal end.

Young males $(\mathrm{n}=2)$

Figs. 12a, b

Young males 2403, 2456 long and 66, 79 wide. Body cuticle thick and transversely striated. Well sclerotised yellowish brown buccal capsule (45, 52 long and 32, 38 wide) without striations. Oesophagus with anterior muscular $(195,212)$ and posterior glandular $(234,246)$ moieties. Nerve-ring and deirids at 112, 116 and 161, 166, respectively, from anterior end. Spicules broad proximally and taper to pointed tip. Left spicule 66, 79 long and much shorter than right spicule $(321,331)$. Gubernaculum strongly sclerotised, Y-shaped and yellowish in colour. Caudal papillae number 14-15 pairs: 8-9 pairs preanals, 1 pair adanals and 5 pairs postanals. Phasmids posterior to last pair of postanal papillae. Tail 58, 63 long, with obtuse tip.

Young females $(\mathrm{n}=3)$

Figs. 14a, b, 22

Young females 3174-3578 long, 85-95 wide and bear thick cuticle with transverse striations. Buccal capsule smooth-walled, 53-67 long and 49-57 wide. Muscular and glandular oesophagus 227-266 and 291-340 long, respectively. Nerve-ring surrounds muscular oesophagus at its anterior half, 119-147 from head end. Deirids at a short distance below nerve-ring, 163-166 from anterior end. Excretory pore posterior to deirids, 188-208 from cephalic extremity. Ovary fairly large, its anterior tip reaches near posterior end of oesophagus. Uterine branches extend to a long distance both anteriorly and posteriorly. Vulva at second half of body, 129-164 from posterior end. Vulval lips clearly elevated. Vagina narrow and directed backwards. Phasmids at 49-52 from tail end. Tail 79-118 long, ending in three small mucrones. Maturation time of female could not be determined due to insufficient number of experimental fish.

\section{DISCUSSION}

The course of the development of Procamallanus saccobranchi follows basically that of other members of the family Camallanidae. In the intermediate copepod hosts the first-stage larvae undergo two moults to give the third stage. Between the two moults, growth, development and morphometric changes occur (Table 1). De et al. (1986) studied the development of P. spiculogubernaculus in the intermediate copepod hosts, Mesocyclops obsolatus and $M$. oithonoides at three different temperature regimes $\left(20-28^{\circ} \mathrm{C}, 29-35^{\circ} \mathrm{C}\right.$ and $35-37^{\circ} \mathrm{C}$ ) and observed that at $20-28^{\circ} \mathrm{C}$ water temperatures the larvae attained the second stage between days 3 and 8 p.i. (first moulting was, however, reported to occur on day 7 p.i.) and the second moult occurred between days 4 and 12 p.i. In the present case, at water temperatures $28-30^{\circ} \mathrm{C}$, the first and second moults occurred on days 3 and 5 p.i., respectively. The morphology of the first- and second-stage larvae of $P$. saccobranchi resembles that of other camallanid genera so far studied. Free first-stage larva has a characteristic dorsal tooth at the cephalic end, oesophagus in form of a thin-walled tube with spacious cavity inside ("preoesophageal" state) and an elongated tail. The consistency of the "pre-oesophageal" state seems to be an important feature of developing L1 larvae. Subsequently, the body cuticle and the oesophageal wall become thick and the dorsal tooth becomes reduced and eventually casts off along with cuticle during the first moulting. During transition from L1 to L2 the oesophagus becomes indistinctly separated into anterior muscular and posterior glandular moieties. In the second stage the larval body enlarges but tail becomes shorter. Gradually a small hyaline "cap" appears at the anterior end of muscular oesophagus and leads to the formation of the buccal capsule prior to second moult. Welldifferentiated buccal capsule is, however, seen after the second moult. The oesophagus at the second stage is distinctly separated into anterior muscular and posterior glandular parts. Late second-stage (prior to second moult) larva with short and wide tail terminating in three distinct mucrones within the old cuticle represents a transitional phase between L2 and L3. The larvae at their third stage, however, show some differences, particularly in the structure of the buccal capsule.

The buccal capsule of the third-stage larvae of Procamallanus and Spirocamallanus species, e.g., $P$. laeviconchus (Wedl, 1862), S. fulvidraconis (Li, 1935), S. mysti (Karve, 1952), P. spiculogubernaculus, S. rebecae Andrade-Salas, Pineda-López et García Magaña, 1994, is without a distinct separation into anterior and posterior portions (Moravec 1975, Li 1935, De 1995, De et al. 1986, Moravec et al. 1995). The third-stage larvae of Onchocamallanus bagarii (Karve et Naik, 1951) also possess an undivided buccal capsule (De and Maity 1999). But those of S. cearensis (Pereira, Dias et Azevedo, 1936) (=S. hilarii Vaz et Pereira, 1934), S. pimelodus (Pinto, Fabio, Noronha et Rolas, 1974), S. cricotus Fusco et Overstreet, 1978 and S. neocaballeroi Caballero-Deloya, 1977 possess a capsule with a well separated, spacious posterior portion (Pereira et al. 1936, Moravec et al. 1993, Fusco 1980, Moravec and Vargas-Vázquez 1996). The buccal capsule of the present third-stage larvae is smooth, 
without spiral thickenings on the inner surface, by which it resembles the third-stage larvae of $S$. fulvidraconis, S. mysti, S. rebecae (Li 1935, Bashirullah and Ahmed 1976, De 1995, Moravec et al. 1995). The buccal capsule of the third-stage larvae of $O$. bagarii is also smooth and without spiral thickenings on the inner surface (De and Maity 1999). But the third-stage larvae of $S$. cearensis and $S$. cricotus possess the buccal capsule with spiral thickenings (Pereira et al. 1936, Fusco 1980). The tail of the third-stage larvae of $P$. saccobranchi, as some other species e.g., S. fulvidraconis, S. cricotus, S. neocaballeroi and O. bagarii bears three mucrones (Li 1935, Fusco 1980, Moravec and Vargas-Vázquez 1996, De and Maity 1999), while four in P. laeviconchus and S. cearensis (Moravec 1975, Pereira et al. 1936).

In order to study the larval development in the definitive hosts, the copepods bearing third and infective-stage larvae were forcibly pushed into the stomach of the laboratory reared fish, $H$. fossilis. In the stomach of the fish hosts the larvae undergo two further moults involving further differentiation, particularly of the buccal capsule, gonads and the caudal end, to attain the adult stage (Table 2). The moulting third-stage larvae were recovered on day 13 p.i. The fourth-stage "male" and "female" larvae were also first recovered on day 13 p.i. The "male" and "female" larvae undergoing the fourth moult were collected on day 38 and 66 p.i., respectively. Young males and young females were also recovered on day 38 and 66 p.i., respectively.

The life cycle of $P$. spiculogubernaculus was described incompletely by Sinha (1988). It was only mentioned that the third- and infective-stage larvae required 138-164 days to become sexually mature adult in the definitive hosts in normal laboratory conditions but the life-cycle stages in the fish host were neither described nor illustrated. As to the rate of development of other species, De (1995) observed that the third larval moult of $S$. mysti in the definitive host occurred on day 15 p.i. and the last (fourth) moult of "male" and "female" larvae on days 37 and 67 p.i., respectively. Moravec et al. (1995) estimated "from their experiment" that the third and fourth moults of $S$. rebecae larvae in the definitive fish host, Cichlasoma urophthalmus, took place on days 13-14 p.i. and day 42 p.i., respectively, at $25-32^{\circ} \mathrm{C}$. Moravec and Vargas-Vázquez (1996) presumed that the third and fourth moults of $S$. neocaballeroi larvae occurred in the definitive fish host, Astyanax fasciatus on day 10 p.i. and days $14-15$ p.i., respectively, at $25-32^{\circ} \mathrm{C}$. In the present case the larvae underwent the third moult on day 13 p.i. and the fourth moult of "male" and "female" larvae occurred on day 38 p.i. and day 66 p.i., respectively.

\section{REFERENCES}

BASHIRULLAH A.K.M., AHMED B. 1976: Larval development of Spirocamallanus intestinecolas (Bashirullah, 1973), Bashirullah, 1974 in copepods. Riv. Parassitol. 37: 303-311.

DE N.C. 1995: On the development and life cycle of Spirocamallanus mysti (Nematoda: Camallanidae). Folia Parasitol. 42: 135-142.

DE N.C., MAITY R.N. 1999: Larval development of Onchocamallanus bagarii (Nematoda: Camallanidae) in copepods. Folia Parasitol. 46: 53-58.

DE N.C., SINHA R.K., MAJUMDAR G. 1986: Larval development of Procamallanus spiculogubernaculus Agarwal, 1958 (Nematoda: Camallanidae) in copepods. Folia Parasitol. 33: 51-60.

FUSCO A.C. 1980: Larval development of Spirocamallanus cricotus (Nematoda: Camallanidae). Proc. Helminthol. Soc. Wash. 47: 63-71.

LI H.C. 1935: The taxonomy and early development of Procamallanus fulvidraconis n. sp. J. Parasitol. 21: 102113.

MORAVEC F. 1975: The development of Procamallanus laeviconchus (Wedl, 1862) (Nematoda: Camallanidae). Acta Soc. Zool. Bohemoslov. 39: 23-38.

MORAVEC F., VARGAS-VÁZQUEZ J. 1996: The development of Procamallanus (Spirocamallanus) neocaballeroi
(Nematoda: Camallanidae), a parasite of Astyanax fasciatus (Pisces) in Mexico. Folia Parasitol. 43: 61-70.

MORAVEC F., KOHN A., FERNANDES B.M.M. 1993: Nematode parasites of fishes of the Paraná River, Brazil. Part 3. Camallanoidea and Dracunculoidea. Folia Parasitol. 40: 211-229.

MORAVEC F., MENDOZA-FRANCO E., VARGASVÁZQUEZ J., VIVAS-RODRÍGUEZ C. 1995: Studies on the development of Procamallanus (Spirocamallanus) rebecae (Nematoda: Camallanidae) a parasite of cichlid fishes in Mexico. Folia Parasitol. 42: 281-292.

PEREIRA C., DIAS M.V., AZEVEDO P. 1936: Biologia do nematoide "Procamallanus caerensis" n. sp. Arch. Inst. Biol. Sao Paulo 7: 209-226 + 2 plts.

ROY R. 1987: Some aspects of piscine nematodes and transcuticular absorption. PhD. Thesis. Burdwan University, Burdwan, $106 \mathrm{pp}$.

SINHA A.K. 1988: On the life cycle of Procamallanus spiculogubernaculus (Camallanidae) (Agarwal, 1958) a nematode parasite of fishes. Riv. Parassitol. 49: 111-116.

WANG P., LING X. 1975: Some nematodes of the suborder Camallanata from Fujian Province, with notes on their life histories. Acta Zool. Sin. 21: 350-358.

Accepted 7 March 2000 